\title{
Downregulation of BAG-1 in T47D cells promotes resistance to tamoxifen via activation of the PI3K/Akt/mTOR signaling pathway
}

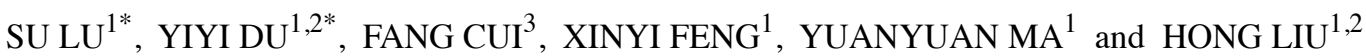 \\ ${ }^{1}$ Tianjin Medical University Cancer Institute and Hospital, National Clinical Research Center for Cancer, \\ Key Laboratory of Cancer Prevention and Therapy, Key Laboratory of Breast Cancer Prevention and Therapy, \\ Tianjin Medical University, Ministry of Education, Tianjin 300060; ${ }^{2}$ The Second Surgical Department of \\ Breast Cancer Oncology, Tianjin Medical University, Cancer Institute and Hospital, Tianjin 300060; \\ ${ }^{3}$ Department of Oncology, Yixing Hospital Affiliated to Jiangsu University, \\ Yixing, Jiangsu 214200, P.R. China
}

Received January 10, 2018; Accepted January 16, 2019

DOI: $10.3892 /$ or.2019.6978

\begin{abstract}
Tamoxifen, a selective estrogen receptor (ER) modulator, is the most widely used endocrine therapy for patients with ER-positive breast cancer. However, $30 \%$ of tamoxifen-treated breast cancers do not initially respond to tamoxifen, and neither do they eventually develop tamoxifen resistance. Bcl-2-associated athanogene 1 (BAG-1) is a multifunctional protein that interacts with a wide range of molecules to protect cells from apoptosis otherwise induced by cytotoxic drugs, growth factor withdrawal, radiation and stress. The aim of the present study was to investigate the function of BAG-1 in tamoxifen resistance. Immunohistochemistry techniques were used to determine BAG-1 expression in 119 stage I-III primary breast cancer tissues and it was identified that BAG-1 was significantly overexpressed in ER-positive breast cancer $(\mathrm{P}=0.001)$. Knockdown of BAG-1 by short interfering RNA was revealed to downregulate ER, and upregulate phospho (p)-protein kinase B (Akt) and p-mammalian target of rapamycin (mTOR) levels. Furthermore, significantly decreased tamoxifen-induced apoptosis $(41.70 \pm 1.93$ vs. $55.03 \pm 2.39 \% ; \mathrm{P}=0.012$ ) was observed in T47D cells following the silencing of BAG-1. In contrast, overexpression of BAG-1 long enhanced apoptosis $(65.10 \pm 2.35$ vs. $55.03 \pm 2.39 \%$; $\mathrm{P}=0.039)$ in T47D cells treated with tamoxifen. Combination
\end{abstract}

Correspondence to: Professor Hong Liu, Tianjin Medical University Cancer Institute and Hospital, Huanhu Xi Road, Tiyuanbei, Tianjin 300060, P.R. China

E-mail: liuhong@tjmuch.com

*Contributed equally

Key words: Bcl-2-associated athanogene 1, breast cancer, tamoxifen resistance, phosphoinositide 3-kinase/protein kinase B/mammalian target of rapamycin pathway, rapamycin treatment of tamoxifen and an mTOR inhibitor restored the inhibitory effects of tamoxifen in T47D cells exhibiting low BAG-1 expression levels $(66.87 \pm 2.27$ vs. $57.07 \pm 2.46 \%$; $\mathrm{P}=0.037$ ). In conclusion, there results of the present study indicated that suppression of BAG-1 expression may activate the phosphoinositide 3-kinase/Akt/mTOR pathway and protect ER-positive breast cancer cells from tamoxifen-induced inhibition of proliferation. ER-positive breast cancer cells exhibiting low BAG-1 expression appeared to be more sensitive to treatment with the mTOR inhibitor rapamycin. Furthermore, the results indicated that combination treatment targeting ER with tamoxifen and targeting mTOR with rapamycin may significantly potentiate the inhibitory effect in BAG-1-silenced cells.

\section{Introduction}

Breast cancer is a heterogeneous disease, presenting with distinctive clinical features, behavior and responses to therapy. An estimated 70-80\% of breast cancer cases express estrogen receptor (ER) (1-3). The therapeutic management of ER-positive cancer includes the application of tamoxifen, which is a selective ER modulator that competes with estrogen for binding with ER. Theoretically, patients with ER-positive breast cancer should benefit from treatment with tamoxifen and other endocrine agents (such as aromatase inhibitors). However, a proportion of breast cancer cases fail to initially respond, whereas certain types of breast cancer develop acquired resistance to endocrine therapy over time. Novel therapeutic approaches are required to enhance the efficacy of endocrine therapy and overcome resistance exhibited by breast cancer.

Mammalian target of rapamycin (mTOR), a serine/ threonine protein kinase and a downstream member of the phosphoinositide 3-kinase (PI3K)/protein kinase B (Akt) signaling pathway, is a crucial regulator of cell proliferation and metabolism. A previous study identified that ER-positive cells exposed to long-term culture in estrogen-deprived medium became more dependent on the mTOR signaling pathway for 
proliferation and exhibit greater sensitivity to inhibition of the mTOR signaling pathway (4), which suggests that inhibition of this signaling pathway using an mTOR inhibitor may restore sensitivity to tamoxifen. Rapamycin and its analogs represent promising candidates for the suppression of mTOR pathway activity.

Bcl-2-associated athanogene 1 (BAG-1) is a multifunctional protein that interacts with a wide range of molecules and subsequently affects various cellular functions (5-10). BAG-1 protects cells from apoptosis otherwise induced by treatment with cytotoxic drugs, growth factor withdrawal, radiation and stress (11-15). BAG-1 is expressed in three main isoforms, which differ in their translation initiation starting positions (16,17). BAG-1 long (BAG-1L; p50) has been reported to enhance ER function and to be associated with disease outcomes in patients with ER-positive breast cancer receiving endocrine therapy $(18,19)$. BAG-1 mRNA has also been revealed to represent a prognostic biomarker in Oncotype DX (20). Although the significance of BAG-1 as a biomarker in ER-positive breast cancer has been well-established, little is known about the molecular mechanism underlying the association between BAG-1 and the cellular response to tamoxifen. In the present study, BAG-1 expression was assessed in clinical breast cancer specimens. In breast cancer cells, multiple approaches were used to investigate the function of BAG-1 in endocrine therapy and to investigate the underlying molecular mechanisms of the association of BAG-1 with breast cancer endocrine resistance.

\section{Materials and methods}

Tumor tissues and immunohistochemistry analysis. Human breast cancer tissue microarrays (TMAs) were purchased from Shanghai Outdo Biotech Co., Ltd. (Shanghai, China; cat. no. HBre-Duc159Sur-01). Informed consent was obtained from all patients according to Shanghai Outdo Biotech Co., Ltd., and the study protocol was approved by the Ethics Committee of Tianjin Medical University Cancer Institute and Hospital (Tianjin, China). The TMA slides included 119 cases of invasive ductal carcinoma of stages I-III, and 40 cases of normal adjacent tissue. Slides $(5-\mu \mathrm{m})$ were deparaffinized and rehydrated through a graded series of ethanol. Following antigen retrieval, slides were blocked for endogenous peroxidase activity in $3 \% \mathrm{H}_{2} \mathrm{O}_{2}$ and were blocked in $5 \%$ normal goat serum blocking solution (OriGene Technologies, Inc., Beijing, China) for $1 \mathrm{~h}$ at room temperature. Tissue sections were incubated with rabbit anti-BAG-1 primary antibodies (1:100; cat. no. ab32109; Abcam, Cambridge, UK) overnight at $4^{\circ} \mathrm{C}$. Slides were incubated with a biotinylated mouse anti-hemagglutinin tag rabbit secondary antibody $(1: 1,000$; cat. no. TA183062; OriGene Technologies, Inc.) for $2 \mathrm{~h}$ at room temperature. Each section was treated with horseradish peroxidase-conjugated streptavidin (OriGene Technologies, Inc.) and subsequently stained using 3,3'-diaminobenzidine (1:20) at room temperature. The nuclei were counterstained with hematoxylin for $1 \mathrm{~min}$ at room temperature.

Staining of BAG-1 in the nucleus and cytoplasm was described in terms of intensity $(0$, absent; $1+$, weak; $2+$, moderate; $3+$, intense) and the total percentage of cells exhibiting positive staining (0-100\%). Calculation of H-scores was on the basis of the percentage of positively stained cells multiplied by the staining intensity score, with $\mathrm{H}$-scores ranging between 0 and 300 (18). An H-score of $>100$ was considered to indicate a positive result. Evaluation was carried out by four independent observers.

Cell culture and treatment. T47D breast cancer cells (American Type Culture Collection, Manassas, VA, USA) were maintained in RPMI-1640 medium (Gibco; Thermo Fisher Scientific, Inc., Waltham, MA, USA) with $10 \%$ fetal bovine serum (Gibco; Thermo Fisher Scientific, Inc.) and $100 \mathrm{U} / 100 \mu \mathrm{g}$ penicillin/ streptomycin (Gibco; Thermo Fisher Scientific, Inc.) at $37^{\circ} \mathrm{C}$ in a humidified $5 \% \mathrm{CO}_{2}$ incubator (Sanyo Electric Co., Ltd., Osaka, Japan). 4-Hydroxytamoxifen (4-OH TAM), an active metabolite of tamoxifen, and rapamycin were purchased from Sigma-Aldrich; Merck KGaA (Darmstadt, Germany).

Cell transfection. BAG-1 short interfering RNA (siRNA; Guangzhou RiboBio Co., Ltd., Guangzhou, China) sequences used for transfection were as follows: 5'-CCACAAUAGAGC AGUUUAU-3' (sense) and 3'-GGUGUUAUCUCGUCAAAU A-5' (antisense). A scrambled siRNA (Guangzhou RiboBio Co., Ltd.) was used in parallel. Overexpression of BAG-1L was achieved by transfecting GV144-BAG-1 (Shanghai GeneChem Co., Ltd., Shanghai, China) into T47D cells and T47D cells transfected with an empty vector GV144 (cytomegalovirus-enhanced green fluorescent protein-multiple cloning site-simian virus 40-neomycin) were used as a control. Transfection was performed using Lipofectamine ${ }^{\mathrm{TM}} 3000$ reagent (Thermo Fisher Scientific, Inc.), according to the manufacturer's protocol. Briefly, between $2 \times 10^{5}$ and $3 \times 10^{5}$ cells/well were seeded into 6-well plates and incubated overnight in medium in the absence of antibiotics. The following day, 2-4 $\mu \mathrm{g}$ plasmids were mixed with Lipofectamine ${ }^{\mathrm{TM}} 3000$, and the mixture was subsequently added to each well. The cells were then incubated at $37^{\circ} \mathrm{C}$ in a $\mathrm{CO}_{2}$ incubator for $24 \mathrm{~h}$. Following incubation, cells were prepared for subsequent assays.

Western blot analysis. Cells were lysed on ice using radioimmunoprecipitation assay mammalian cell lysis reagent (Beijing Solarbio Science \& Technology Co., Ltd., Beijing, China) containing phenylmethylsulfonyl fluoride (Sigma; Merck KGaA). Subsequently, cell lysates were centrifuged at $16,000 \mathrm{x}$ for $20 \mathrm{~min}$ at $4^{\circ} \mathrm{C}$, and the protein concentration was subsequently determined using a Bicinchoninic Acid assay kit (Beijing Solarbio Science \& Technology Co., Ltd.). Following separation of denatured proteins $(20-50 \mu \mathrm{g})$ by SDS-PAGE (8-15\% gels), proteins were transferred onto a polyvinylidene difluoride membrane using a transfer system (Bio-Rad Laboratories, Inc., Hercules, CA, USA) at $250 \mathrm{~mA}$ for 1-3 h, and the membrane was blocked in $5 \%$ non-fat milk for $1 \mathrm{~h}$ at room temperature prior to incubation with the following primary antibodies overnight at $4^{\circ} \mathrm{C}$ : Anti-BAG-1 (1:500; cat. no. 3920; Cell Signaling Technology, Inc., Danvers, MA, USA), anti-ER (1:1,000; cat. no. 8644; Cell Signaling Technology, Inc.), anti-mTOR (1:1,000; cat. no. 2983; Cell Signaling Technology, Inc.), anti-phospho (p-)mTOR (1:1,000; cat. no. 2971; Cell Signaling Technology, Inc.), anti-Akt (1:1,000; cat. no. 9272; Cell Signaling Technology, Inc.), anti-p-Akt (Ser ${ }^{473} ; 1: 1,000$; cat. no. 4060; Cell Signaling Technology, Inc.) and anti- $\beta$-actin 
(1:10,000; cat. no. sc-47778; Santa Cruz Biotechnology, Inc., Dallas, TX, USA). The membrane was washed three times in TBST (Tris-buffered saline containing $0.05 \%$ Tween-20) and incubated with horseradish peroxidase-conjugated goat anti-mouse (1:3,000; cat. no. 7076; Cell Signaling Technology, Inc.) or anti-rabbit secondary antibodies (1:3,000; cat. no. 7074; Cell Signaling Technology, Inc.) for $2 \mathrm{~h}$ at room temperature. Following washing with TBST, proteins were visualized using the Enhanced Chemiluminescence detection reagent (EMD Millipore, Billerica, MA, USA) and analyzed using a Gel Doc 1000 instrument (Bio-Rad Laboratories, Inc.). All western blotting was performed three times.

Reverse transcription-quantitative polymerase chain reaction $(R T-q P C R)$. Total RNA was extracted using TRIzol ${ }^{\circledR}$ reagent (Invitrogen; Thermo Fisher Scientific, Inc.), according to the manufacturer's protocol. cDNA was synthesized from $0.5 \mu \mathrm{g}$ total RNA using a PrimeScript RT reagent kit (Takara Bio, Inc., Otsu, Japan), according to the manufacturer's protocol. qPCR was carried out in triplicate using a CFX96 real-time PCR system (Bio-Rad Laboratories, Inc.) and SYBR Premix Ex Taq II (Takara Bio, Inc.). The cycling conditions were $50^{\circ} \mathrm{C}$ for $2 \mathrm{~min}, 95^{\circ} \mathrm{C}$ for $10 \mathrm{~min}$, followed by 40 cycles of $95^{\circ} \mathrm{C}$ for $15 \mathrm{sec}$ and $60^{\circ} \mathrm{C}$ for $30 \mathrm{sec} . \beta$-actin was used as an internal control. Relative quantification of BAG-1 and ER expression levels was performed using the $2^{-\Delta \Delta C q}$ method (21). The sequences of the primers used were as follows: BAG-1, 5'-GTT CTTTGGATGGAGCCTGTG-3' (forward) and 5'-TGCCTG CTTTACTCATTCTGGTG-3' (reverse); ER $\alpha, 5^{\prime}$-TCAGGC ACATGAGTAACAAAGG-3' (forward) and 5'-AAGGAA TGCGATGAAGTAGAGC-3' (reverse); $\beta$-actin, 5'-TGACGT GGACATCCGCAAACG-3' (forward) and 5'-CTGGAAGGT GGACAGCGAGG-3' (reverse).

Cell cycle and apoptosis analysis. Cells were incubated in RPMI-1640 medium with $10 \%$ fetal bovine serum with $10 \mu \mathrm{mol} / 14-\mathrm{OH}$ TAM and/or $10 \mu \mathrm{mol} / 1 \mathrm{rapamycin}$. Cells were harvested after $48 \mathrm{~h}$ by trypsinization.

Cell cycle analysis was investigated using a cell cycle detection kit (Nanjing KeyGen Biotech Co., Ltd., Nanjing, China). Following harvesting of drug-treated cells, the cells were collected and fixed using ice-cold $70 \%$ ethanol in PBS for $24 \mathrm{~h}$ at $4^{\circ} \mathrm{C}$. Cells were treated with RNase A for $30 \mathrm{~min}$, labeled with propidium iodide for $30 \mathrm{~min}$ at $37^{\circ} \mathrm{C}$ in the dark and subsequently analyzed via flow cytometry. Cell apoptosis assays were performed using an Annexin V-allophycocyanin (APC)/7-aminoactinomycin D (7-AAD) nuclear peridininchlorophyll protein complex (PerCP) Apoptosis Detection kit (Nanjing KeyGen Biotech Co., Ltd.), according to the manufacturer's protocol. Cells were resuspended in binding buffer, incubated with Annexin V-APC followed by 7-AAD at room temperature for $15 \mathrm{~min}$ in the dark and subsequently analyzed by flow cytometry using a FACSCanto II flow cytometer (BD Biosciences, San Jose, CA, USA). All experiments were performed in triplicate.

Statistical analysis. All statistical analyses were performed using GraphPad Prism (version 6.02; GraphPad Software, Inc., La Jolla, CA, USA). A $\chi^{2}$ test was used to determine statistically significant differences among clinicopathological
Table I. Association of BAG-1 expression with clinicopathological features of patients with breast cancer included in the tissue microarray.

\begin{tabular}{|c|c|c|c|c|}
\hline \multirow[b]{2}{*}{ Characteristic } & \multirow[b]{2}{*}{ Total no. ${ }^{b}$} & \multicolumn{2}{|c|}{$\begin{array}{c}\text { BAG-1 } \\
\text { expression }\end{array}$} & \multirow[b]{2}{*}{ P-value $\left(\chi^{2}\right)$} \\
\hline & & Low & High & \\
\hline Age, years & & & & 0.820 \\
\hline$<50$ & 54 & 15 & 39 & \\
\hline$\geq 50$ & 64 & 19 & 45 & \\
\hline Tumor size, $\mathrm{cm}$ & & & & 0.022 \\
\hline$\leq 5$ & 96 & 28 & 78 & \\
\hline$>5$ & 12 & 7 & 5 & \\
\hline Tumor grade & & & & $<0.001$ \\
\hline I & 40 & 21 & 19 & \\
\hline $\mathrm{II}+\mathrm{III}$ & 79 & 14 & 65 & \\
\hline Nodal status & & & & 0.458 \\
\hline Negative & 43 & 15 & 28 & \\
\hline Positive & 64 & 18 & 46 & \\
\hline $\mathrm{ER}^{\mathrm{a}}$ & & & & 0.001 \\
\hline Negative & 43 & 20 & 23 & \\
\hline Positive & 75 & 14 & 61 & \\
\hline $\mathrm{PR}^{\mathrm{a}}$ & & & & 0.003 \\
\hline Negative & 51 & 22 & 29 & \\
\hline Positive & 66 & 12 & 54 & \\
\hline HER-2a & & & & 0.002 \\
\hline Negative & 89 & 20 & 69 & \\
\hline Positive & 30 & 15 & 15 & \\
\hline
\end{tabular}

${ }^{\mathrm{a}}$ As retrieved from TMA. ${ }^{\mathrm{b}} \mathrm{O}$ wing to missing information, numbers do not always total 119. IHC, immunohistochemistry; ER, estrogen receptor; PR, progesterone receptor; HER-2, human epidermal growth factor 2 .

features. Data are presented as the mean \pm standard deviation. Student's t-test or one-way analysis of variance followed by Tukey's multiple comparisons test was used to determine the differences between groups. $\mathrm{P}<0.05$ was considered to indicate a statistically significant difference.

\section{Results}

BAG-1 is highly expressed in ER-positive breast cancer. To assess the function of BAG-1 and its association with ER status in human breast cancer, immunohistochemistry was performed using TMAs including 119 human breast invasive ductal carcinoma cases (Table I). The expression rate of BAG-1 protein was $95.8 \%(114 / 119)$. BAG-1 was localized in either the nucleus or the cytoplasm, and the majority of specimens exhibited positive nuclear and cytoplasmic staining results (Fig. 1A). The association of BAG-1 expression with the principal clinicopathological features of patients with breast cancer included in the TMA are summarized in Table I. Overexpression of 
A

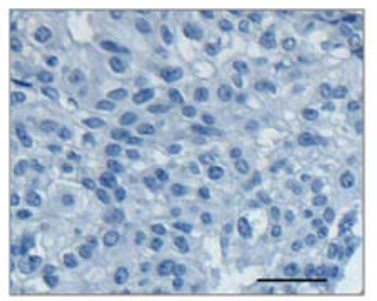

BAG-1/Low

B

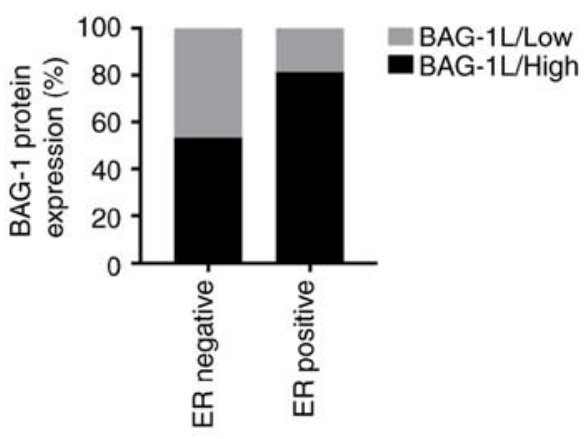

Figure 1. Immunohistochemical staining of BAG-1 in breast cancer tissue microarrays. (A) Representative images of immunohistochemical staining using BAG-1 in breast cancer specimens. Scale bar, $20 \mu \mathrm{m}$. (B) BAG-1 expression in $\mathrm{ER}^{+}$and $\mathrm{ER}^{-}$breast cancer tissues. BAG-1, Bcl-2-associated athanogene 1; ER, endoplasmic reticulum.
BAG-1 was positively associated with ER positivity $(\mathrm{P}=0.001$; Fig. 1B), progesterone receptor positivity $(\mathrm{P}=0.003)$, tumor size $(\mathrm{P}=0.022)$ and tumor grade $(\mathrm{P}<0.001)$, but negatively associated with human epidermal growth factor receptor-2 amplification status $(\mathrm{P}=0.004)$. To verify the association between BAG-1 and ER expression, BAG-1L, which has been identified previously (22) tointeract with numerous other nuclear hormone receptors was investigated. BAG-1L expression levels were determined using western blotting and RT-qPCR. The results indicated that BAG-1L was overexpressed in T47D cells (Fig. 2A and B). Expression of ER mRNA was increased almost 7-fold, and enhanced expression of ER protein was also observed in $\mathrm{T} 47 \mathrm{D} / \mathrm{BAG}-1 \mathrm{~L}^{+}$cells at $48 \mathrm{~h}$ post-transfection using western blot analysis (Fig. 2C and D). In addition, the expression levels of ER protein and mRNA following knockdown of BAG-1 were decreased (Fig. 2C and D).

Modulation of BAG-1 expression affects the proliferation of T47D cells treated with tamoxifen. Tamoxifen has been identified to significantly improve survival rates of patients with breast cancer. However, patients treated with tamoxifen remain at risk of cancer recurrence and mortality owing to drug resistance. To investigate the potential association between BAG-1 and the response to tamoxifen exhibited by ER-positive cells,
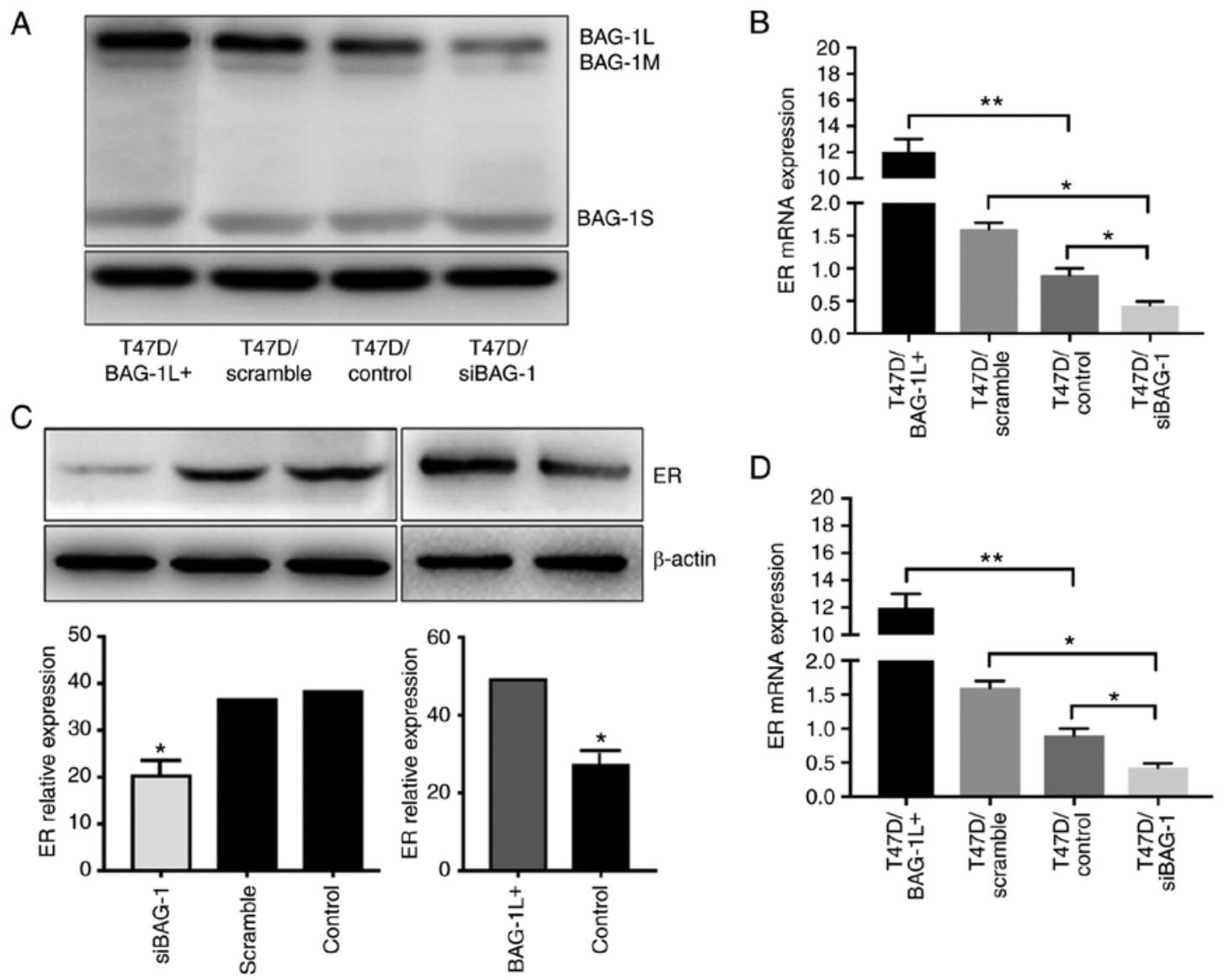

Figure 2. BAG-1 expression in T47D cells is positively associated with ER expression. (A) Representative western blot analysis of T47D cells overexpressing BAG-1L (T47D/BAG-1L ${ }^{+}$), and T47D cells transfected with vector controls (T47D/control) or with scrambled siRNA (T47D/scramble) and siRNA (T47D/siBAG-1). $\beta$-actin was used as a loading control. (B) BAG-1 mRNA expression in T47D/BAG-1L $\mathrm{L}^{+}, \mathrm{T} 47 \mathrm{D} / \mathrm{control}$ and T47D/siBAG-1 and T47D/scramble siRNA cells. (C) Representative western blot analyses of ER proteins in T47D/BAG-1L+, T47D/control, T47D/siBAG-1 cells at $48 \mathrm{~h}$ post-transfection. $\beta$-actin was used as a loading control. (D) mRNA expression of ER in T47D/BAG-1L+, T47D/control, T47D/siBAG-1 and T47D/scramble siRNA cells. BAG-1, Bcl-2-associated athanogene 1; BAG-1L, BAG-1 long; si/siRNA, short interfering RNA; ER, estrogen receptor; BAG-1M, BAG-1 medium; BAG-1S, BAG-1 short. ${ }^{*} \mathrm{P}<0.05,{ }^{* *} \mathrm{P}<0.001$ (one-way analysis of variance followed by Tukey's multiple comparisons test). 
B

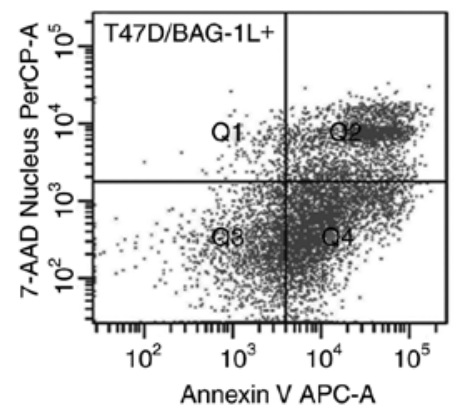

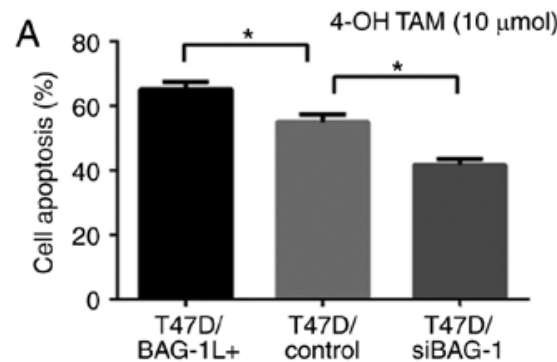
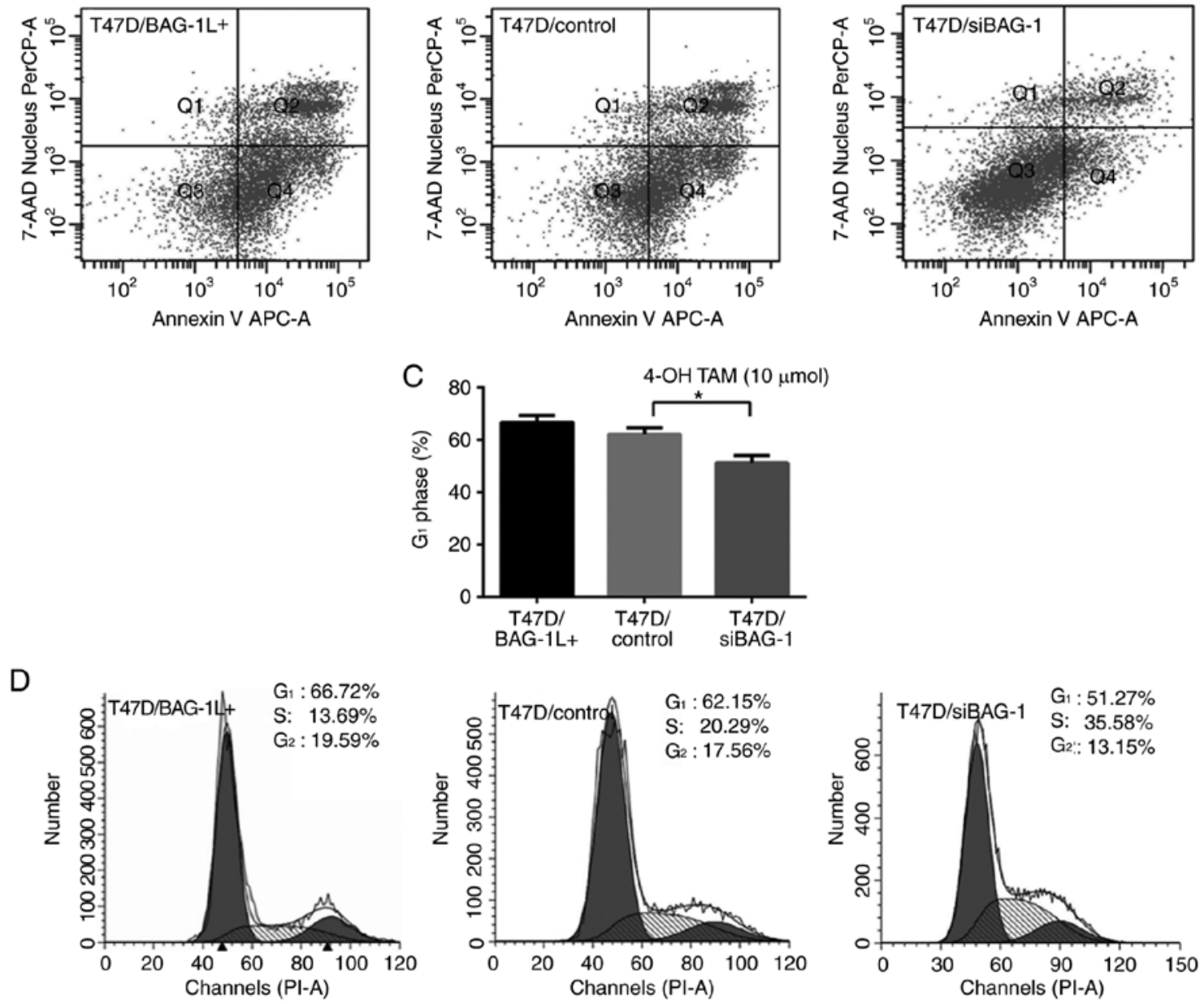

Figure 3. Modulation of BAG-1 expression affects the proliferation of ER-positive cells treated with tamoxifen. (A) T47D/BAG-1L $\mathrm{L}^{+}$T47D/control and T47D/siBAG-1 cells were cultured in 4-OH TAM $(10 \mu \mathrm{mol} / 1)$ for $48 \mathrm{~h}$. Cell apoptosis was determined using flow cytometry. (B) Representative flow cytometric plots of Annexin V assays using three groups of cells treated with 4-OH TAM $(10 \mu \mathrm{mol} / \mathrm{l})$ for $48 \mathrm{~h}$. (C) Quantification of $\mathrm{G}_{1}$-phase cells in T47D/BAG-1L ${ }^{+}$, T47D/control and T47D/siBAG-1 cells after $48 \mathrm{~h}$ of treatment with 4-OH TAM $(10 \mu \mathrm{mol} / \mathrm{l})$. (D) Representative cell cycle histograms of T47D/BAG-1L ${ }^{+}$ T47D/control and T47D/siBAG-1 cells after $48 \mathrm{~h}$ of treatment with 4-OH TAM $(10 \mu \mathrm{mol} / 1)$. " $\mathrm{P}<0.05$ (one-way ANOVA with Tukey's multiple comparisons test; n=3). BAG-1, Bcl-2-associated athanogene 1; BAG-1L, BAG-1 long; 4-OH TAM, 4-hydroxytamoxifen; si, short interfering RNA; 7-AAD, 7-aminoactinomycin D; PerCP, peridinin-chlorophyll protein complex; APC, allophycocyanin; PI, propidium iodide.

cells were treated with 4-OH TAM at a concentration of $10 \mu \mathrm{mol} / \mathrm{l}$ for $48 \mathrm{~h}$, and cell cycle and apoptosis analyses were performed to determine cell proliferation. BAG-1 silencing led to a decreased apoptosis rate $(41.70 \pm 1.93$ vs. $55.03 \pm 2.39 \%$; $\mathrm{P}=0.012$; Fig. $3 \mathrm{~A}$ and $\mathrm{B}$ ) when compared with control cells following treatment with $10 \mu \mathrm{mol} / 1$ 4-OH TAM. In contrast, T47D cells overexpressing BAG-1L exhibited significantly increased levels of 4-OH TAM-induced apoptosis at a concentration of $10 \mu \mathrm{mol} / 1(65.10 \pm 2.35$ vs. $55.03 \pm 2.39 \%$; $\mathrm{P}=0.039$; Fig. 3A and B). Furthermore, a decreased proportion of T47D/siBAG-1 cells was blocked in $\mathrm{G}_{1}$ phase compared with that of control cells $(51.27 \pm 2.67$ vs. $62.15 \pm 2.46 \% ; \mathrm{P}=0.007$;
Fig. 3C and D) following treatment with $10 \mu \mathrm{mol} / 14-\mathrm{OH}$ TAM. In addition, cells overexpressing BAG-1L exhibited a slightly increased proportion of cells in $\mathrm{G}_{1}$ phase compared with that of control cells $(66.72 \pm 2.63$ vs. $62.15 \pm 2.46 \%$; $\mathrm{P}=0.093$; Fig. $3 \mathrm{C}$ and D). Taken together, these results indicated that BAG-1L overexpression may enhance the sensitivity of ER-positive cells to treatment with tamoxifen, and silencing of BAG-1 may attenuate the proliferation-inhibitory effect of tamoxifen in ER-positive cells.

mTOR inhibitor restores tamoxifen sensitivity in ER-positive breast cancer cells. The MTOR protein is a critical component 
A

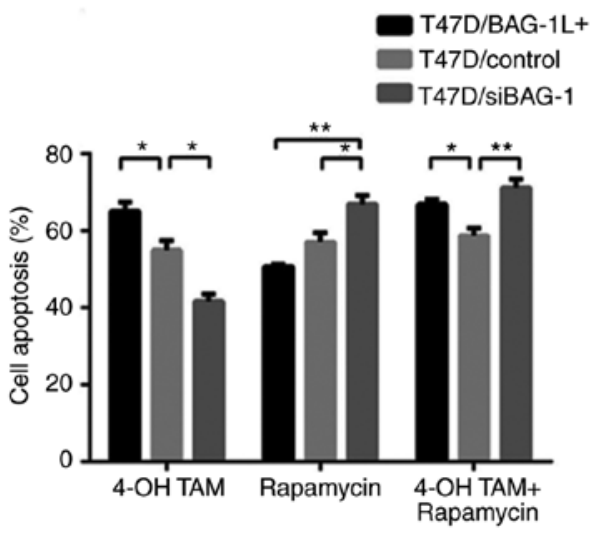

B

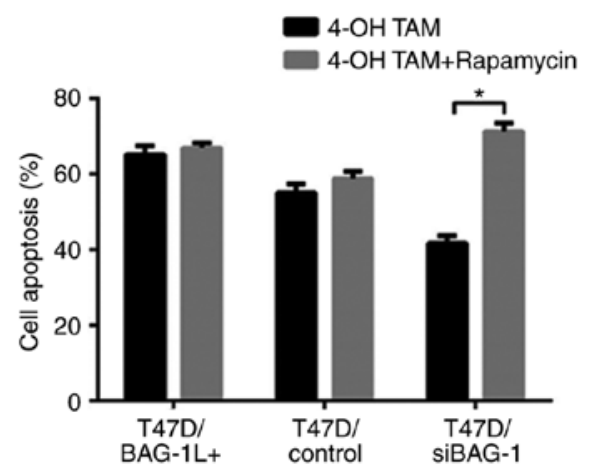

C
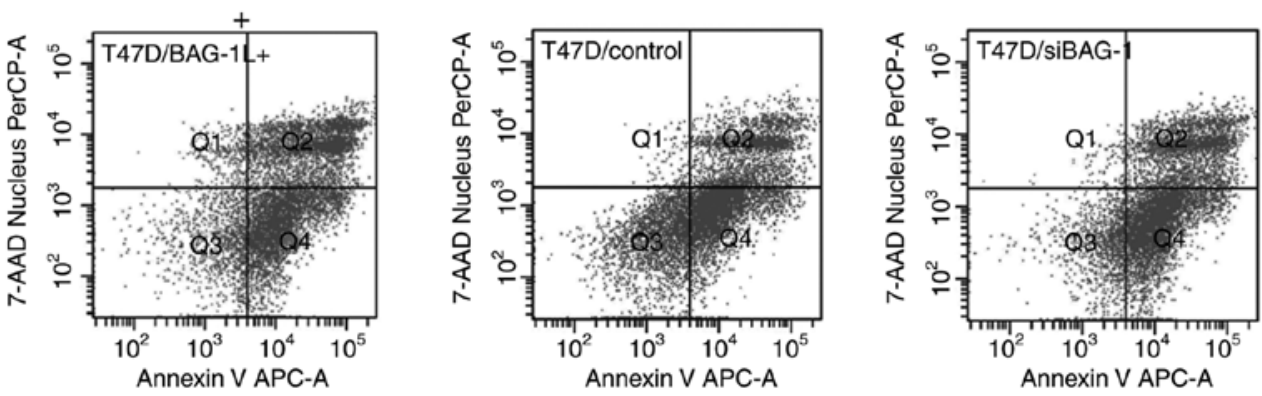

D

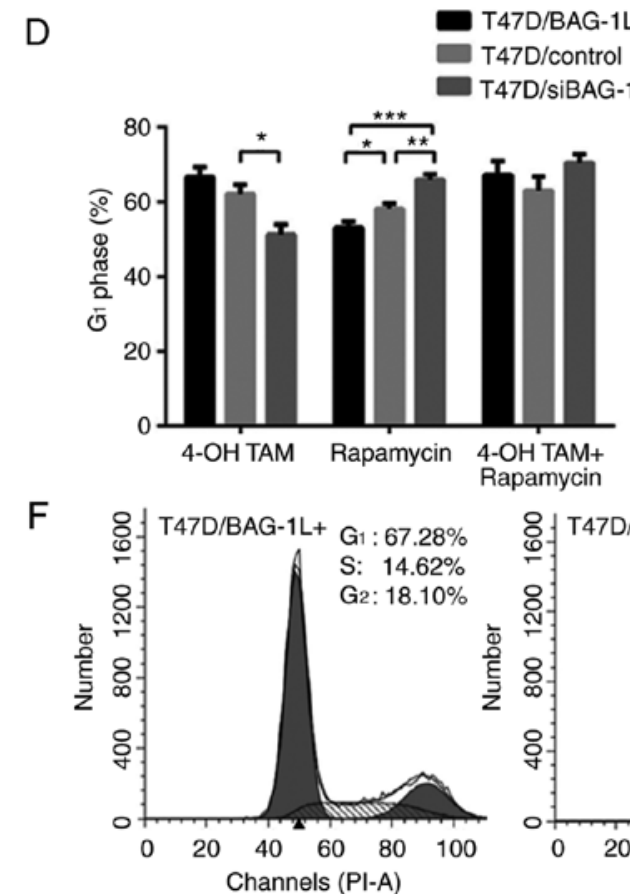

E

- 4-OH TAM

4-OH TAM+Rapamycin
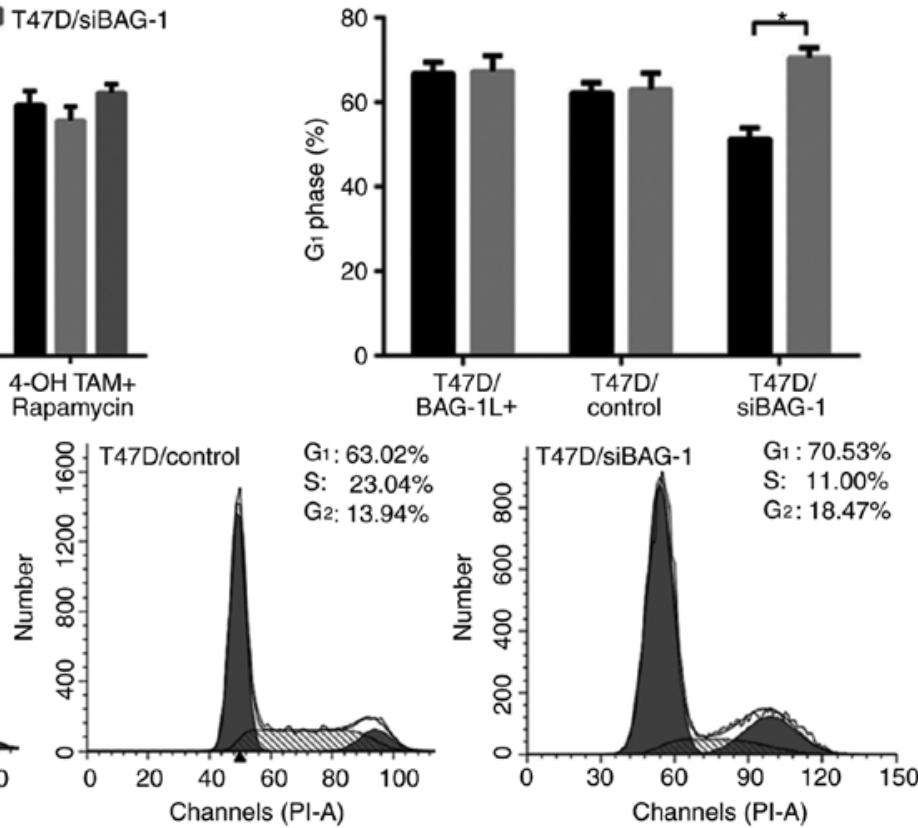

Figure 4. Rapamycin restores cell sensitivity to 4-OH TAM. (A) T47D/BAG-1L+, T47D/control and T47D/siBAG-1 cells were cultured with either 4-OH TAM $(10 \mu \mathrm{mol} / 1)$ or rapamycin $(10 \mu \mathrm{mol} / 1)$ alone, or with $4-\mathrm{OH} \mathrm{TAM}(10 \mu \mathrm{mol} / \mathrm{l})$ in combination with rapamycin $(10 \mu \mathrm{mol} / 1)$, for $48 \mathrm{~h}$. Cell apoptosis was determined using flow cytometry. ${ }^{*} \mathrm{P}<0.05,{ }^{* *} \mathrm{P}<0.01$ (one-way ANOVA with Tukey's multiple comparisons test; $\mathrm{n}=3$ ). (B) T47D/BAG-1L $\mathrm{L}^{+}$, T47D/control and T47D/siBAG-1 cells were cultured with either 4-OH TAM $(10 \mu \mathrm{mol} / \mathrm{l})$ alone, or with 4-OH TAM $(10 \mu \mathrm{mol} / \mathrm{l})$ in combination with rapamycin $(10 \mu \mathrm{mol} / \mathrm{l})$, for $48 \mathrm{~h}$. Cell apoptosis was determined using flow cytometry. $\mathrm{P}<0.05$ (Student's t-test; $\mathrm{n}=3$ ). (C) Representative flow cytometric plots of annexin assays using T47D cells treated with a combination of 4-OH TAM $(10 \mu \mathrm{mol} / \mathrm{l})$ and rapamycin $(10 \mu \mathrm{mol} / \mathrm{l})$ for $48 \mathrm{~h}$. (D) Quantification of G $\mathrm{G}_{1}$-phase cells in T47D/BAG-1L $\mathrm{L}^{+}$T47D/control and T47D/siBAG-1 cells after $48 \mathrm{~h}$ of treatment with either 4-OH TAM $(10 \mu \mathrm{mol} / \mathrm{l})$ or rapamycin $(10 \mu \mathrm{mol} / \mathrm{l})$ alone, or with 4-OH TAM $(10 \mu$ mol/l) in combination with rapamycin $(10 \mu \mathrm{mol} / 1) .{ }^{*} \mathrm{P}<0.05,{ }^{* *} \mathrm{P}<0.01,{ }^{* * *} \mathrm{P}<0.001$ (one-way ANOVA with Tukey's multiple comparisons test; $\mathrm{n}=3$ ). (E) Quantification of $\mathrm{G}_{1}$-phase cells in T47D/BAG-1L ${ }^{+}$, T47D/control and T47D/siBAG-1 cells after $48 \mathrm{~h}$ of treatment with 4-OH TAM (10 $\mu \mathrm{mol} / \mathrm{l})$ and rapamycin $(10 \mu \mathrm{mol} / 1)$ in combination. ${ }^{*} \mathrm{P}<0.05$ (Student's t-test; $\mathrm{n}=3$ ). (F) Representative cell cycle histograms of T47D/BAG-1L $\mathrm{L}^{+}, \mathrm{T} 47 \mathrm{D} /$ control and T47D/siBAG-1 cells after $48 \mathrm{~h}$ of treatment with 4-OH TAM (10 $\mu$ mol/l) and rapamycin $(10 \mu \mathrm{mol} / 1)$ in combination. 4-OH TAM, 4-hydroxytamoxifen; BAG-1, Bcl-2-associated athanogene 1; BAG-1L, BAG-1 long; si, short interfering RNA; ANOVA, analysis of variance; 7-AAD, 7-aminoactinomycin D; PerCP, peridinin-chlorophyll protein complex; APC, allophycocyanin; PI, propidium iodide.

in the PI3K/Akt/mTOR signaling pathway, which is a key intracellular signaling system involving in multiple cellular processes, including proliferation and survival. Hyperactivation of this pathway is associated with cell resistance to endocrine therapy (23). The mTOR inhibitor rapamycin was reported to be able to reverse endocrine therapy resistance exhibited by 
A

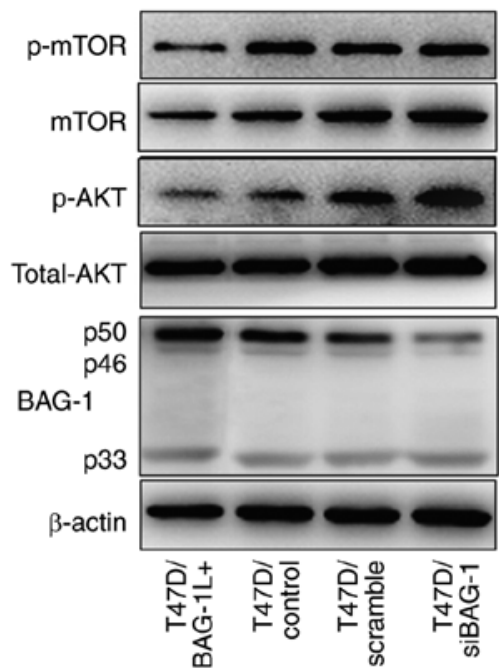

B

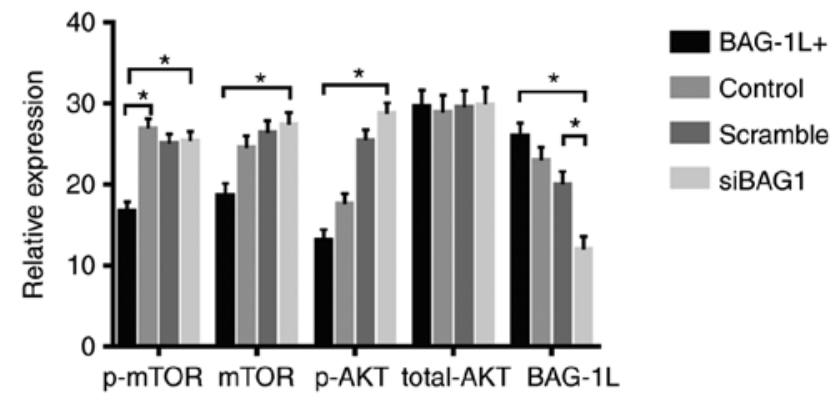

Figure 5. Western blot analysis of protein levels of p-mTOR, mTOR, p-Akt, Akt, BAG-1 and $\beta$-actin in T47D/BAG-1L+, T47D/control, T47D/siBAG-1 and T47D/scramble siBAG-1 cells. (A) Representative western blot images. (B) Quantitative analysis. " $\mathrm{P}<0.05$ one-way ANOVA with Tukey's multiple comparisons test; n=3. p-, phospho-; mTOR, mammalian target of rapamycin; Akt, protein kinase B; BAG-1, Bcl2-associated athanogene 1; BAG-1L, BAG-1 long; si, short interfering RNA.

breast cancer cells $(24,25)$. To demonstrate whether the inhibition of mTOR signaling was able to restore cell sensitivity to treatment with tamoxifen, T47D/BAG-1L + , T47D/control and $\mathrm{T} 47 \mathrm{D} / \mathrm{siBAG}-1$ cells were treated with either $4-\mathrm{OH}$ TAM or rapamycin alone, or 4-OH TAM in combination with rapamycin at a concentration based on a predetermined half-maximal inhibitory concentration. The results suggested that T47D/siBAG-1 cells were more susceptible to treatment with rapamycin alone compared with the two other groups of cells (T47D/siBAG-1 vs. T47D/BAG-1L ${ }^{+}, 66.87 \pm 2.27$ vs. $50.7 \pm 0.59 \% ; \mathrm{P}=0.003 ; \mathrm{T} 47 \mathrm{D} / \mathrm{siBAG}-1$ vs. $\mathrm{T} 47 \mathrm{D} /$ control, $66.87 \pm 2.27$ vs. $57.07 \pm 2.46 \% ; \mathrm{P}=0.037$; $\mathrm{T} 47 \mathrm{D} / \mathrm{BAG}-1 \mathrm{~L}^{+}$vs T47D/control, $50.7 \pm 0.59$ vs. $57.07 \pm 2.46 \%$; $\mathrm{P}=0.173$; Fig. $4 \mathrm{~A})$. T47D/siBAG-1 cells exposed to combination treatment exhibited a greater increase in susceptibility to rapamycin treatment compared with the two other groups of cells (T47D/siBAG-1 vs. T47D/control vs. T47D/BAG- $1 \mathrm{~L}^{+}, 71.23 \pm 2.23$ vs. $58.8 \pm 1.89$ vs. $66.93 \pm 1.27 \%$; $\mathrm{P}=0.008$; Fig. $4 \mathrm{~A}$ ). Furthermore, rapamycin markedly enhanced 4-OH TAM-induced apoptosis in T47D/siBAG-1 cells $(41.70 \pm 1.93$ vs. $71.23 \pm 2.23 \%$; $\mathrm{P}<0.001$; Fig. 4B, whereas levels of apoptotic cell death were slightly increased in T47D/BAG-1L ${ }^{+}$cells $(65.1 \pm 2.35$ vs. $66.93 \pm 1.27 \%$; $\mathrm{P}=0.531$; Fig. $4 \mathrm{C}$ and $\mathrm{T} 47 \mathrm{D} /$ control cells $(55.03 \pm 2.39$ vs. $58.8 \pm 1.89 \%$; $\mathrm{P}=0.284$; Fig. 4B). Representative results of cell apoptosis $48 \mathrm{~h}$ after treatment are presented in Fig. 4C.

Analysis of the cell cycle was performed to assess the inhibition of proliferation mediated by treatment with 4-OH TAM and rapamycin either separately or in combination. The proportion of cells in $\mathrm{G}_{1}$ phase was increased following treatment with a combination of 4-OH TAM and rapamycin compared with cells treated with 4-OH TAM alone. T47D/siBAG-1 cells exhibited a more marked increase in $\mathrm{G}_{1}$ arrest (70.53 \pm 2.30 vs. $51.27 \pm 2.67 \%$; $\mathrm{P}<0.001$; Fig. 4D), whereas the proportion of cells in $\mathrm{G}_{1}$ phase in the control group $(63.02 \pm 3.80$ vs. $62.15 \pm 2.46 \%$; $\mathrm{P}=0.755$; Fig. 4D) and the T47D/BAG- $1 \mathrm{~L}^{+}$group $(67.28 \pm 3.80$ vs. $66.72 \pm 2.63 \%$; $\mathrm{P}=0.840$; Fig. 4D) was only slightly increased compared with that of T47D/siBAG-1 group. The results indicated that a greater proportion of T47D/siBAG-1 cells were arrested in $G_{1}$ phase compared with the other two groups $48 \mathrm{~h}$ after combination treatment; however, the differences were not statistically significant (T47D/siBAG-1 vs. T47D/control vs. T47D/BAG-1L $\mathrm{L}^{+}, 70.533 \pm 2.30$ vs. $63.02 \pm 3.80$ vs. $66.72 \pm 2.63 \%$; $\mathrm{P}=0.086$; Fig. $4 \mathrm{E})$. Overall, these results indicated that rapamycin could restore sensitivity to 4-OH TAM in ER-positive breast cancer cells, particularly in cells exhibiting low levels of BAG-1 expression. Representative results of the cell cycle distribution $48 \mathrm{~h}$ after combination treatment of 4-OH TAM and rapamycin are presented in Fig. 4F.

Additionally, the protein levels of total Akt, p-Akt, total mTOR and p-mTOR in cells overexpressing BAG-1 and in BAG-1-knockdown cells were investigated. The results of western blot analysis revealed a noticeable increase in p-Akt and p-mTOR levels in T47D cells following the silencing of BAG-1 expression, whereas upregulation of $\mathrm{BAG}-1 \mathrm{~L}$ was revealed to decrease levels of p-Akt and p-mTOR (Fig. 5A and B). This suggests that Akt/mTOR signaling was activated in BAG-1-silenced cells.

\section{Discussion}

ER is expressed in the majority of patients with breast cancer. The functions of estrogen and anti-estrogen are associated with ER expression. Previous studies have yielded inconsistent results regarding the association between BAG-1 expression and ER status in breast cancer. The first study analyzing this association was published in 1999 and exhibited increased levels of positive BAG-1 nuclear or cytoplasmic staining in the majority of ER-positive breast cancer tumors compared with ER-negative tumors (26); however, no statistical analysis was performed owing to the limited sample size. A further cohort study of 122 female patients with stage I to II breast cancer failed to identify an association between BAG-1 expression and ER positivity (27). In a more homogeneous and larger cohort study including 138 breast cancer cases, BAG-1 expression 
was identified to be moderately correlated with ER (19). A further two studies identified the positive correlation between BAG-1 and ER expression $(18,28)$. The association between BAG-1 protein and ER expression has also been investigated in endometrial cancer, which is another estrogen-dependent cancer. No significant difference between the ER-negative and ER-positive groups was identified in the proportion of samples exhibiting positive BAG-1 expression (29). Explanations for these inconsistent results may include differences in the antibodies used, differing immunohistochemistry techniques and scoring methods, and a different proportion of patients with ER-positive breast cancer in the clinical cohorts. In the present study, total BAG-1 protein expression was investigated via immunohistochemistry using 119 breast cancer cases. It was identified that high BAG-1 expression was associated with ER-positive breast cancer. In addition, in vitro experiments were performed, which revealed that knockdown of BAG-1 subsequently downregulated ER expression in ER-positive breast cancer cells. In contrast, BAG-1 overexpression was demonstrated to upregulate ER expression. However, subcellular localization of associated isoforms was not investigated in the present study. Further studies are required to determine the respective contribution of specific isoforms to the association between BAG-1 and ER expression. In conclusion, this association between BAG-1 and ER expression suggested that BAG-1 may have a function in the response to endocrine therapy in ER-positive breast cancer. The PI3K/Akt/mTOR signaling pathway is able to promote cell proliferation in the absence of estrogen via activation of estrogen-independent ER transcription activity (23). Thus, hyperactivation of this pathway may contribute to endocrine resistance by promoting hormone-independent proliferation.

Previous clinical studies have revealed that enhanced BAG-1 protein expression in breast cancer specimens is an independent factor that may predict a favorable outcome in ER-positive patients receiving endocrine therapy $(18,19)$. BAG-1 was included as a favorable predictive biomarker in the Oncotype DX test. In accordance with these published results, it was identified in the present study that increased BAG-1 expression levels were associated with enhanced responses to tamoxifen in breast cancer cells, whereas knockdown of BAG-1 expression led to attenuated inhibition of cell proliferation. Furthermore, enhanced levels of p-Akt and p-mTOR were observed in cells following silencing of BAG-1 expression. On the basis of the results of the present and previous studies $(4,30)$ suggesting that activation of the mTOR signaling pathway promotes anti-estrogen resistance, we hypothesized that BAG-1 may represent an inhibitor of the PI3K/Akt/mTOR signaling pathway and may be associated with tamoxifen resistance. Knockdown of BAG-1 expression activated this pathway, resulting in decreased sensitivity to tamoxifen. Furthermore, an association between BAG-1 overexpression and resistance to tamoxifen in MCF-7 cells was observed (Lu et al, unpublished data). Such differing results may be due to the following factors: Different cell lines with distinct biological characteristics used for investigation, complex crosstalk in cellular signaling pathways and different concentrations of tamoxifen used to treat cells.

The PI3K/Akt/mTOR signaling pathway is frequently activated in breast cancer $(31,32)$. Activation of this pathway has been associated with resistance to endocrine therapy in patients with ER-positive breast cancer (33-35). Pre-clinical studies have revealed that the mTOR inhibitor rapamycin and its analogs may reverse endocrine resistance in ER-positive breast cancer cells with activated PI3K/Akt/mTOR signaling pathways $(30,36)$. Clinical trials have demonstrated that combined treatment of everolimus and tamoxifen, or a combinatory treatment of everolimus and exemestane, are more effective than the use of either endocrine agent alone in patients who have become resistant to endocrine therapy and their disease state has progressed. The BOLERO-2 trial was a phase III randomized trial that compared the combinatory treatment of everolimus (an mTOR inhibitor) and exemestane with treatment using a placebo and exemestane in post-menopausal women with HR-positive advanced breast cancer. Improved progression-free survival was observed in patients treated with a combination of everolimus and exemestane (10.6 vs. 4.1 months; $\mathrm{P}<0.0001)$ (37). The TAMRAD trail evaluated the efficacy of treatment with tamoxifen alone compared with combinatory treatment with tamoxifen and everolimus in patients with aromatase inhibitor-resistant metastatic breast cancer. This study revealed that combinatory treatment with tamoxifen and everolimus significantly improved the clinical benefit rate (61 vs. $42 \% ; \mathrm{P}=0.045)$ and progression rates (8.6 vs. 4.5 months; $\mathrm{P}=0.002$ ) (38). Considering the possible involvement of BAG-1 in the mTOR pathway, the inhibitory effect on cells was assessed following silencing of BAG-1 expression post-treatment with tamoxifen alone as well as post-combinatory treatment with tamoxifen and rapamycin. The results of the present study indicated that rapamycin is able to restore the sensitivity of ER-positive breast cancer cells to treatment with 4-OH TAM. Furthermore, cells exhibiting decreased BAG-1 expression appeared to have a greater sensitivity to rapamycin, and combinatory treatment involving the targeting of ER with tamoxifen and the targeting of mTOR with rapamycin significantly potentiated inhibition of cell proliferation following the silencing of BAG-1 expression. These results may be partly due to hyperactivation of the PI3K/Akt/mTOR signaling pathway induced by the downregulation of the BAG-1 pathway inhibitor. A previous study has revealed that overactivity of the PI3K/Akt/mTOR signaling pathway may result in ER-positive cells exhibiting a greater sensitivity to rapamycin and its analogs (27). In further work, animal experiments are required, using animals with high expression of target genes and gene knockout animals, or using in vivo injection blockers to further verify the results of cell experiments to explore the function of BAG-1 in tamoxifen resistance and its potential underlying molecular mechanism.

In conclusion, the results of the present study revealed that loss of BAG-1 expression may activate the PI3K/Akt/mTOR signaling pathway and protect ER-positive breast cancer cells from tamoxifen-induced inhibition of proliferation. ER-positive breast cancer cells with low BAG-1 expression appeared to exhibit a greater sensitivity to treatment with the mTOR inhibitor rapamycin. Furthermore, the results of the present study suggested that combinatory treatment targeting ER with tamoxifen and targeting mTOR with rapamycin may significantly potentiate the proliferation inhibitory effect in cells following the silencing of BAG-1. 


\section{Acknowledgements}

Not applicable.

\section{Funding}

This research did not receive any specific grant from funding agencies in the public, commercial or not-for-profit sectors.

\section{Availability of data and materials}

All data generated or analyzed during this study are included in this published article.

\section{Authors' contributions}

HL made substantial contributions to conception and design. SL contributed to acquisition of data, and analysis and interpretation of data. YD drafted and revised the manuscript. XF performed the histological examination of the breast cancer. FC and YM contributed to critical revision of the manuscript. All authors approved the paper and HL gave the final approval of the version to be published.

\section{Ethics approval and consent to participate}

Human breast cancer tissue microarrays (TMAs) were purchased from Shanghai Outdo Biotech Co., Ltd. (Shanghai, China; cat. no. HBre-Duc159Sur-01). Informed consent was obtained from all patients according to Shanghai Outdo Biotech Co., Ltd., and the study protocol was approved by the Ethics Committee of Tianjin Medical University Cancer Institute and Hospital. All procedures performed in studies involving human participants were in accordance with the ethical standards of the institutional and/or national research committee, and with The Declaration of Helsinki (1964) and its later amendments, or comparable ethical standards.

\section{Patient consent for publication}

Not applicable.

\section{Competing interests}

The authors declare that they have no competing interests.

\section{References}

1. Setiawan VW, Monroe KR, Wilkens LR, Kolonel LN, Pike MC and Henderson BE: Breast cancer risk factors defined by estrogen and progesterone receptor status: The multiethnic cohort study. Am J Epidemiol 169: 1251-1259, 2009.

2. Li CI, Daling JR and Malone KE: Incidence of invasive breast cancer by hormone receptor status from 1992 to 1998 . J Clin Oncol 21: 28-34, 2003.

3. Systemic treatment of early breast cancer by hormonal, cytotoxic, or immune therapy. 133 randomised trials involving 31,000 recurrences and 24,000 deaths among 75,000 women. Early Breast Cancer Trialists' Collaborative Group. Lancet 339: 71-85, 1992.

4. Yue W, Fan P, Wang J, Li Y and Santen RJ: Mechanisms of acquired resistance to endocrine therapy in hormone-dependent breast cancer cells. J Steroid Biochem Mol Biol 106: 102-110, 2007.
5. Takayama S, Sato T, Krajewski S, Kochel K, Irie S, Millan JA and Reed JC: Cloning and functional analysis of BAG-1: A novel $\mathrm{Bcl}-2$-binding protein with anti-cell death activity. Cell 80: 279-284, 1995.

6. Wang HG, Takayama S, Rapp UR and Reed JC: Bcl-2 interacting protein, BAG-1, binds to and activates the kinase Raf-1. Proc Natl Acad Sci USA 93: 7063-7068, 1996.

7. Takayama S, Bimston DN, Matsuzawa S, Freeman BC, Aime-Sempe C, Xie Z, Morimoto RI and Reed JC: BAG-1 modulates the chaperone activity of Hsp70/Hsc70. EMBO J 16: 4887-4896, 1997.

8. Devireddy LR, Kumar KU, Pater MM and Pater A: BAG-1, a novel Bcl-2-interacting protein, activates expression of human JC virus. J Gen Virol 81: 351-357, 2000.

9. Zhou R, Gray NA, Yuan P, Li X, Chen J, Chen G, Damschroder-Williams P, Du J, Zhang L and Manji HK: The anti-apoptotic, glucocorticoid receptor cochaperone protein BAG-1 is a long-term target for the actions of mood stabilizers. J Neurosci 25: 4493-4502, 2005.

10. Hinitt CA, Wood J, Lee SS, Williams AC, Howarth JL, Glover CP, Uney JB and Hague A: BAG-1 enhances cell-cell adhesion, reduces proliferation and induces chaperone-independent suppression of hepatocyte growth factor-induced epidermal keratinocyte migration. Exp Cell Res 316: 2042-2060, 2010.

11. Clemo NK, Collard TJ, Southern SL, Edwards KD, Moorghen M, Packham G, Hague A, Paraskeva C and Williams AC: BAG-1 is up-regulated in colorectal tumour progression and promotes colorectal tumour cell survival through increased NF-kappaB activity. Carcinogenesis 29: 849-857, 2008.

12. Wang YD, Ha MW, Cheng J, Zhang WL, Cong X, Tong CY and Sun J: The role of expression and polymorphism of the BAG-1 gene in response to platinum-based chemotherapeutics in NSCLC. Oncol Rep 27: 979-986, 2012.

13. Ni W, Chen B, Zhou G, Lu C, Xiao M, Guan C, Zhang Y, He S, Shen A and Ni R: Overexpressed nuclear BAG-1 in human hepatocellular carcinoma is associated with poor prognosis and resistance to doxorubicin. J Cell Biochem 114: 2120-2130, 2013.

14. Ozfiliz P, Kizilboga T, Demir S, Alkurt G, Palavan-Unsal N, Arisan ED and Dinler-Doganay G: Bag-1 promotes cell survival through c-Myc-mediated ODC upregulation that is not preferred under apoptotic stimuli in MCF-7 cells. Cell Biochem Funct 33: 293-307, 2015.

15. Papadakis E, Robson N, Yeomans A, Bailey S, Laversin S, Beers S, Sayan AE, Ashton-Key M, Schwaiger S, Stuppner H, et al: A combination of trastuzumab and BAG-1 inhibition synergistically targets HER2 positive breast cancer cells. Oncotarget 7: 18851-18864, 2016.

16. Packham G, Brimmell M and Cleveland JL: Mammalian cells express two differently localized Bag-1 isoforms generated by alternative translation initiation. Biochem J 328: 807-813, 1997.

17. Takayama S, Krajewski S, Krajewska M, Kitada S, Zapata JM, Kochel K, Knee D, Scudiero D, Tudor G, Miller GJ, et al: Expression and location of Hsp70/Hsc-binding anti-apoptotic protein BAG-1 and its variants in normal tissues and tumor cell lines. Cancer Res 58: 3116-3131, 1998.

18. Millar EK, Anderson LR, McNeil CM, O'Toole SA, Pinese M, Crea P, Morey AL, Biankin AV, Henshall SM, Musgrove EA, et al: BAG-1 predicts patient outcome and tamoxifen responsiveness in ER-positive invasive ductal carcinoma of the breast. $\mathrm{Br}$ J Cancer 100: 123-133, 2009.

19. Cutress RI, Townsend PA, Sharp A, Maison A, Wood L, Lee R, Brimmell M, Mullee MA, Johnson PW, Royle GT, et al: The nuclear BAG-1 isoform, BAG-1L, enhances oestrogen-dependent transcription. Oncogene 22: 4973-4982, 2003.

20. Paik S, Shak S, Tang G, Kim C, Baker J, Cronin M, Baehner FL, Walker MG, Watson D, Park T, et al: A multigene assay to predict recurrence of tamoxifen-treated, node-negative breast cancer. $\mathrm{N}$ Engl J Med 351: 2817-2826, 2004.

21. Livak KJ and Schmittgen TD: Analysis of relative gene expression data using real-time quantitative PCR and the $2^{-\Delta \Delta C_{\mathrm{T}}}$ method. Methods 25: 402-408, 2001.

22. Chen JM, Dando PM, Stevens RA, Fortunato M and Barrett AJ: Cloning and expression of mouse legumain, a lysosomal endopeptidase. Biochem J 335: 111-117, 1998.

23. Ciruelos Gil EM: Targeting the PI3K/AKT/mTOR pathway in estrogen receptor-positive breast cancer. Cancer Treat Rev 40: 862-871, 2014. 
24. Ghayad SE, Bieche I, Vendrell JA, Keime C, Lidereau R Dumontet $C$ and Cohen PA: mTOR inhibition reverses acquired endocrine therapy resistance of breast cancer cells at the cell proliferation and gene-expression levels. Cancer Sci 99: 1992-2003, 2008.

25. Chang SB, Miron P, Miron A and Iglehart JD: Rapamycin inhibits proliferation of estrogen-receptor-positive breast cancer cells. J Surg Res 138: 37-44, 2007.

26. Brimmell M, Burns JS, Munson P, McDonald L, O'Hare MJ, Lakhani SR and Packham G: High level expression of differentially localized BAG-1 isoforms in some oestrogen receptor-positive human breast cancers. Br J Cancer 81: 1042-1051, 1999.

27. Turner BC, Krajewski S, Krajewska M, Takayama S, Gumbs AA, Carter D, Rebbeck TR, Haffty BG and Reed JC: BAG-1: A novel biomarker predicting long-term survival in early-stage breast cancer. J Clin Oncol 19: 992-1000, 2001.

28. Naderi A, Teschendorff AE, Barbosa-Morais NL, Pinder SE, Green AR, Powe DG, Robertson JF, Aparicio S, Ellis IO, Brenton JD, et al: A gene-expression signature to predict survival in breast cancer across independent data sets. Oncogene 26: 1507-1516, 2007.

29. Moriyama T, Littell RD, Debernardo R, Oliva E, Lynch MP Rueda BR and Duska LR: BAG-1 expression in normal and neoplastic endometrium. Gynecol Oncol 94: 289-295, 2004.

30. Beeram M, Tan QT, Tekmal RR, Russell D, Middleton A and DeGraffenried LA: Akt-induced endocrine therapy resistance is reversed by inhibition of mTOR signaling. Ann Oncol 18: 1323-1328, 2007.

31. McCubrey JA, Davis NM, Abrams SL, Montalto G, Cervello M, Libra M, Nicoletti F, D'Assoro AB, Cocco L, Martelli AM and Steelman LS: Targeting breast cancer initiating cells: Advances in breast cancer research and therapy. Adv Biol Regul 56: 81-107, 2014.
32. Gonzalez-Angulo AM, Ferrer-Lozano J, Stemke-Hale K, Sahin A, Liu S, Barrera JA, Burgues O, Lluch AM, Chen H, Hortobagyi GN, et al: PI3K pathway mutations and PTEN levels in primary and metastatic breast cancer. Mol Cancer Ther 10: 1093-1101, 2011.

33. Pérez-Tenorio G and Stål O; Southeast Sweden Breast Cancer Group: Activation of AKT/PKB in breast cancer predicts a worse outcome among endocrine treated patients. Br J Cancer 86: 540-545, 2002.

34. Tokunaga E, Kimura Y, Oki E, Ueda N, Futatsugi M, Mashino K, Yamamoto M, Ikebe M, Kakeji Y, Baba $\mathrm{H}$ and Maehara Y: Akt is frequently activated in HER2/neu-positive breast cancers and associated with poor prognosis among hormone-treated patients. Int J Cancer 118: 284-289, 2006.

35. Campbell RA, Bhat-Nakshatri P, Patel NM, Constantinidou D, Ali S and Nakshatri H: Phosphatidylinositol 3-kinase/AKTmediated activation of estrogen receptor alpha: A new model for anti-estrogen resistance. J Biol Chem 276: 9817-9824, 2001.

36. deGraffenried LA, Friedrichs WE, Russell DH, Donzis EJ, Middleton AK, Silva JM, Roth RA and Hidalgo M: Inhibition of mTOR activity restores tamoxifen response in breast cancer cells with aberrant Akt Activity. Clin Cancer Res 10: 8059-8067, 2004.

37. Baselga J, Campone M, Piccart M, Burris HA III, Rugo HS, Sahmoud T, Noguchi S, Gnant M, Pritchard KI, Lebrun F, et al: Everolimus in postmenopausal hormone-receptor-positive advanced breast cancer. N Engl J Med 366: 520-529, 2012.

38. Bachelot T, Bourgier C, Cropet C, Ray-Coquard I, Ferrero JM, Freyer G, Abadie-Lacourtoisie S, Eymard JC, Debled M, Spaëth D, et al: Randomized phase II trial of everolimus in combination with tamoxifen in patients with hormone receptor-positive, human epidermal growth factor receptor 2-negative metastatic breast cancer with prior exposure to aromatase inhibitors: A GINECO study. J Clin Oncol 30: 2718-2724, 2012. 